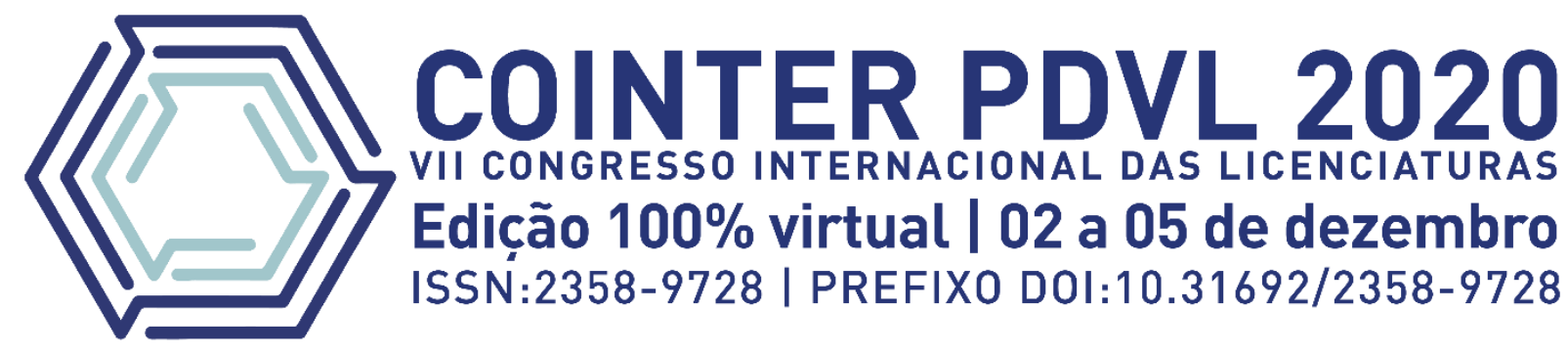

\title{
PERÍODO LETIVO EXCEPCIONAL: PERSPECTIVAS DE DISCENTES DE UMA INSTITUIÇÃO FEDERAL DE ENSINO PERNAMBUCANA
}

\section{PERÍODO DE ESTUDIO EXCEPCIONAL: PERSPECTIVAS DE ESTUDIANTES DE UNA INSTITUCIÓN FEDERAL DE ENSEÑANZA DEL PERNAMBUCO}

\section{EXCEPTIONAL LETTERING PERIOD: PERSPECTIVES OF DISCENTERS OF A FEDERAL INSTITUTION OF PERNAMBUCAN TEACHING}

\author{
Apresentação: Comunicação Oral \\ Yasmim Alline de Araújo Castro ${ }^{1}$; José Sérgio Herculano Gomes da Silva²; Andressa Raquel Maciel Barros \\ Pontes ${ }^{3}$ Carlos Henrique Correia da Silva ${ }^{4}$; Ícaro Fillipe de Araújo Castro ${ }^{5}$
}

DOI: https://doi.org/10.31692/2358-9728.VIICOINTERPDVL.0422

\begin{abstract}
RESUMO
A pandemia relacionada a COVID-19, trouxe mudanças nos campos social, econômico e educacional. Seguindo as medidas de restrição da Organização Mundial de Saúde (OMS), Instituições de Ensino brasileiras suspenderam as atividades presenciais, aderindo inclusive a formas de ensino não presencial. Dessa forma, esse trabalho teve como objetivo conhecer as percepções de discentes de uma Instituição Federal de Ensino Superior cursando disciplinas em Período Letivo Excepcional (PLE). Para alcance dos objetivos, convidou-se licenciandos em biologia cursando disciplinas de forma remota na referida instituição. A participação foi firmada por meio do aceite dos participantes a um Termo de Aceite Livre e Esclarecido (TCLE) e a coleta de dados ocorreu por meio de um questionário semiestruturado, confeccionado a partir da ferramenta Google Forms. Com base nas respostas obtidas no questionário, foi possível notar diversas complicações enfrentadas pelos estudantes durante o PLE, dentre elas problemas relacionados ao acesso aos conteúdos e familiarização com as plataformas utilizadas, a sobrecarga de atividades e problemas de caráter pessoal, transitando até mesmo pela dificuldade em se adaptar às novas circunstâncias. Além disso, as questões discursivas presentes no questionário servem como base para traçar novos caminhos em momentos futuros, visto que proporcionam reflexões e contribuem para o aprimoramento da modalidade de ensino remoto, visando superar as atribulações apontadas pelos estudantes. Isto posto, concluiu-se que as reflexões geradas pelo contexto pandêmico serão extremamente pertinentes para a reformulação da educação brasileira num momento pós-pandemia, uma vez que a substituição do modelo presencial pelo ensino remoto expôs em larga escala as fragilidades que permeiam o processo de ensino e aprendizagem vigente no Brasil.
\end{abstract}

Palavras-Chave: Aulas remotas; Ensino não presencial; Ensino Superior.

\footnotetext{
1 Doutoranda em Biologia Celular e Molecular Aplicada, Universidade de Pernambuco; Licenciatura em Ciências Biológicas, Universidade Federal de Pernambuco, yasmim.castro@ufrpe.br

${ }^{2}$ Licenciatura em Ciências Biológicas, Universidade Federal Rural de Pernambuco, sergio.herculano@ufrpe.br

${ }^{3}$ Licenciatura em Ciências Biológicas, Universidade Federal Rural de Pernambuco, andressa.pontes@ufrpe.br

${ }^{4}$ Licenciatura em Ciências Biológicas, Universidade Federal Rural de Pernambuco, carlos.correiasilva@ufrpe.br

${ }^{5}$ Doutor em Biologia Molecular, IFPI, icaro.castro@ifpi.edu.br
} 


\section{PERÍODO LETIVO ESPECIAI: PERSPECTIVAS DE DISCENTES}

\section{RESUMEN}

La pandemia relacionada con COVID-19 trajo cambios en los campos social, económico y educativo. Siguiendo las medidas de restricción de la Organización Mundial de la Salud (OMS), las Instituciones Educativas Brasileñas suspendieron las actividades presenciales, incluso adhiriéndose a formas de educación no presencial. Así, este trabajo tuvo como objetivo conocer las percepciones de estudiantes de una Institución Federal de Educación Superior que cursan cursos en Periodo Académico Excepcional (PLE). Para lograr los objetivos, se invitó a los egresados de biología a realizar cursos de forma remota en esa institución. La participación se firmó mediante la aceptación de los participantes a un Término de Aceptación Libre e Informado (ICF) y la recolección de datos se realizó mediante un cuestionario semiestructurado, realizado mediante la herramienta de formularios de Google. A partir de las respuestas obtenidas en el cuestionario, se pudo notar varias complicaciones que enfrentaron los estudiantes durante el PLE, entre ellas problemas relacionados con el acceso a los contenidos y familiarización con las plataformas utilizadas, la sobrecarga de actividades y problemas de carácter personal, pasando incluso por la dificultad. en adaptarse a nuevas circunstancias. Además, las preguntas discursivas presentes en el cuestionario sirven de base para trazar nuevos caminos en momentos futuros, ya que brindan reflexiones y aportes para la mejora de la modalidad de enseñanza a distancia, con el objetivo de superar las tribulaciones señaladas por los estudiantes. Dicho esto, se concluyó que las reflexiones generadas por el contexto pandémico serán sumamente pertinentes para la reformulación de la educación brasileña en un momento pospandémico, ya que la sustitución del modelo presencial por educación remota expuso en gran escala las debilidades que permean el proceso de enseñanza y aprendizaje actual en Brasil.

Palabras clave: Clases remotas; Enseñanza no presencial; Enseñanza superior.

\section{ABSTRACT}

The pandemic related to COVID-19 brought changes in the social, economic and educational fields. Following the restriction measures of the World Health Organization (WHO), Brazilian Educational Institutions suspended on-site activities, even adhering to forms of non-on-site education. Thus, this work aimed to get to know the perceptions of students from a Federal Institution of Higher Education taking courses in Exceptional Academic Period (PLE). To achieve the objectives, biology graduates were invited to take courses remotely at that institution. Participation was signed by the participants' acceptance to a Free and Informed Acceptance Term (ICF) and the data collection took place through a semi-structured questionnaire, made using the Google forms tool. Based on the answers obtained in the questionnaire, it was possible to notice several complications faced by students during the PLE, among them problems related to access to content and familiarization with the platforms used, the overload of activities and problems of a personal character, going through even the difficulty in adapting to new circumstances. In addition, the discursive questions present in the questionnaire serve as a basis for tracing new paths in future moments, since they provide reflections and contributions for the improvement of the remote teaching modality, aiming to overcome the tribulations pointed out by the students. That said, it was concluded that the reflections generated by the pandemic context will be extremely pertinent for the reformulation of Brazilian education in a post-pandemic moment, since the substitution of the face-to-face model by remote education exposed on a large scale the weaknesses that permeate the process of current teaching and learning in Brazil.

Key words: Remote classes; Non-classroom teaching; University education.

\section{INTRODUÇÃO}

A pandemia relacionada ao novo coronavírus, SARS-CoV-2, trouxe impactos diversos a saúde pública, economia e ao campo educacional, uma vez que aulas de diversas instituições de ensino ao redor do mundo foram suspensas, principalmente pelo alto potencial epidemiológico da COVID-19 (LANA et al., 2020). Seguindo essa linha, o Brasil também adotou a suspensão de atividades educacionais de forma presencial, com estímulo às 
atividades educacionais não presenciais (BRASIL, 2020 a).

No dia 17 de março de 2020, foi publicada no Diário Oficial da União (DOU) a portaria $\mathrm{n}^{\mathrm{o}} 343$ que dispôs e autorizou a substituição das aulas presenciais por aulas em meios digitais (BRASIL, 2020 ). Atualmente, encontra-se em vigor a portaria $\mathrm{n}^{\mathrm{o}} 544$ de 16 de junho de 2020, que estendeu a autorização até 31 de dezembro de 2020, bem como atribui às Instituições de Ensino a definição dos componentes curriculares que serão substituídos, disponibilização de recursos aos alunos que permitam o acompanhamento das atividades letivas ofertadas, bem como a realização de avaliações durante o referido período da autorização (BRASIL, 2020 ).

Diante disso, o Período Letivo Excepcional (PLE) foi implementado por diversas universidades públicas do país. No PLE, as atividades acadêmicas dos cursos presenciais de graduação são desempenhadas de forma remota, priorizando práticas e modelos de ensino que utilizam primordialmente tecnologias e meios digitais para a realização do processo de ensino e aprendizagem. A Instituição Federal de Ensino de Pernambuco onde a pesquisa foi realizada, após a suspensão do primeiro semestre do ano, aprovou o funcionamento do PLE em julho de 2020, com ação no ensino de graduação. O período excepcional contou com a duração de dez semanas, o limite máximo de 240h de carga horária por aluno, e deixou reservado aos docentes e estudantes o direito de aderir ou não ao semestre sem que ocorram penalizações por parte da universidade.

A necessidade das atividades não presenciais em tempos de pandemia e isolamento social faz pressão nos sistemas de ensino, exigindo meios alternativos para o cumprimento das atividades acadêmicas. Dessa forma, é fundamental que tais atividades ocorram adequadamente e garantam a qualidade do processo de ensino-aprendizagem. Assim, esse trabalho tem como objetivo conhecer as percepções de discentes de uma Instituição Superior Federal de Ensino cursando disciplinas em Período Letivo Excepcional.

\section{FUNDAMENTAÇÃO TEÓRICA}

$\mathrm{Na}$ tentativa de reduzir a ampla difusão da pandemia, medidas de distanciamento social têm sido adotadas por diversos países ao redor do mundo, ainda sem data certa para seu abandono (TODOS PELA EDUCAÇÃO, 2020). As relações sociais foram modificadas, fazendo com que uma nova forma de comportamento social emergisse, alterando as condutas sociais, as formas de se relacionar, bem como o formato de aprendizagem e o trabalho do docente, o que se refletiu nas estratégias de ensino. Esse fenômeno pode ser chamado de Pedagogia Pandêmica, já que se refere a como a educação se organiza diante de tal contexto 


\section{PERÍODO LETIVO ESPECIAI: PERSPECTIVAS DE DISCENTES}

(BARRETO; ROCHA, 2020).

No que diz respeito ao âmbito educacional, o avanço da pandemia da COVID-19 gera impactos de maneira complexa ao passo em que há o transbordamento de efeitos com notáveis assimetrias relacionadas não somente às distintas experiências internacionais de cada país, mas também pelas diferentes respostas internacionais geradas entre o setor público e privado, assim como entre os diferentes níveis de educação (SENHORAS, 2020). A COVID19 levou toda a sociedade a um estado de emergência. A pandemia distanciou os discentes presenciais, da educação básica e do ensino superior, do ambiente físico das instituições de ensino.

Os gestores educacionais ficaram naturalmente atordoados e a reação foi de certa forma tardia. Surgiu, então, a necessidade de se adaptar e de transpor, tanto por parte dos profissionais da educação, quanto pelos discentes (PASINI et al., 2020). No Brasil, redes públicas e privadas interromperam o funcionamento das instituições de ensino e, entre outras ações, transferiram aulas e outras atividades pedagógicas para formatos a distância (TODOS PELA EDUCAÇÃO, 2020).

Diante desse panorama, se fez necessário o uso de saídas que se aproveitam de atividades remotas, estratégia implementada por diversas instituições de ensino em todo o mundo, possibilitando o desenvolvimento de inúmeras discussões em diversas áreas de conhecimento. A partir dessa modalidade educacional, é possível por meio das Tecnologias Digitais da Informação e Comunicação (TDIC) dar continuidade aos processos educativos enquanto as aulas presenciais não retornam (SILVA et al., 2020).

A expansão do ensino remoto requer um planejamento cuidadoso a fim que se evite um agravamento das desigualdades de aprendizagem dentro e entre as redes de educação. Uma transição repentina e em larga escala para tal modalidade sem que haja a preocupação com a capacidade das instituições de ensino em promover aulas de qualidade e a dos discentes em ter a estrutura e o apoio necessários para assimilar os conteúdos disponibilizados tende a reforçar as desigualdades educacionais do Brasil (WORLD BANK, 2020).

\section{METODOLOGIA}

Para alcance dos objetivos propostos por essa pesquisa, licenciandos de uma Instituição Federal de Ensino de Pernambuco foram convidados a participar e expor suas percepções, perspectivas e dificuldades relacionadas ao Período Letivo Excepcional (PLE). Em respeito às normas de saúde impostas pela Organização Mundial de Saúde (OMS), todo o contato e convite aos participantes aconteceu de forma remota, utilizando-se o aplicativo de 
troca de mensagem WhatsApp.

No contato ao participante, foi esclarecido a não obrigatoriedade da participação do mesmo na pesquisa bem como todos os direitos que gozam por meio de um Termo de Consentimento Livre e Esclarecido (TCLE), que os garantia anonimato em suas respostas, retirada de seus dados da pesquisa a qualquer momento prévio a publicação, e garantia aos pesquisadores o direito à publicação dos dados obtidos em meios acadêmicos.

Para coleta de dados, utilizou-se um questionário semiestruturado e confeccionado utilizando-se a ferramenta Google Forms. Posteriormente, a mesma ferramenta, o Google Forms, foi novamente utilizada para fazer a análise dos dados obtidos e para a elaboração dos gráficos a serem utilizados. O questionário continha um total de 13 perguntas, onde as duas primeiras serviam apenas para a caracterização pessoal básica do perfil dos participantes. As quatro perguntas seguintes tinham o objetivo de traçar o perfil dos participantes com em relação ao Período Letivo Excepcional, contendo perguntas referentes aos motivos por terem optado por se matricularem no semestre remoto, se estavam psicologicamente aptos a participarem do PLE, suas condições de acesso à internet e aos conteúdos disponibilizados. As outras sete perguntas eram relativas às suas percepções e experiências que tiveram com o passar das semanas, compreendendo questões sobre sua adaptação ao ensino remoto, suas dificuldades em se familiarizar com as plataformas de ensino escolhidas, os métodos avaliativos utilizados por seus professores e seu processo de construção do conhecimento na modalidade remota.

Ainda em relação às suas percepções, foram realizadas perguntas discursiva, onde os alunos tiveram a oportunidade de comentar livremente sobre sua satisfação com as disciplinas ofertadas, as principais adversidades presenciadas no PLE e sobre possíveis modificações a serem consideradas para que haja um aprimoramento do período excepcional. Todas as respostas obtidas foram analisadas e discutidas na forma de textos, gráficos e tabelas.

\section{RESULTADOS E DISCUSSÃO}

Ao todo, participaram da pesquisa 55 licenciandos em Ciências Biológicas de uma Instituição Federal de Ensino de Pernambuco. Destes, 36 indivíduos (65,5\%) pertenciam ao sexo feminino e 19 (34,5\%), ao sexo masculino. A maioria do grupo amostral foi composta por discentes com faixa-etária entre 18 e 25 anos, que compunham $81,8 \%$ da referida amostra.

$\mathrm{Na}$ primeira questão relacionada ao PLE, indagou-se aos estudantes qual o principal motivo que os levou a participarem do ensino remoto, tendo em vista que não era obrigatório (Figura 01). Nas respostas, 44 participantes (80\%) responderam estar preocupados com 


\section{PERÍODO LETIVO ESPECIAI: PERSPECTIVAS DE DISCENTES}

atrasos em sua formação acadêmica. Sete participantes $(12,7 \%)$, por sua vez, destacaram que a participação no PLE permitia com que os mesmos se tornassem mais produtivos nesse período de pandemia.

Para Joye et al. (2020), o ensino remoto praticado atualmente é semelhante ao EaD, por ser uma educação mediada por TICs (Tecnologias da Informação e Comunicação); entretanto, os princípios continuam os mesmos da educação presencial, tendo em vista que foi um modelo criado em caráter de urgência, por conta da situação atual. Castamani e colaboradores (2020) afirmam que os resultados desse modelo ainda não podem ser vislumbrados, mas alguns desafios já podem ser discutidos. Os docentes precisaram, em um curto espaço de tempo, reaprender/refazer sua forma de acesso aos estudantes, encaminhar atividades e acompanhar de modo mais individual a trajetória de cada um. Essa adaptação em si, é algo que pode demorar um tempo, apesar do imediatismo e da imprevisibilidade da pandemia.

Em uma pesquisa cujo objetivo era descrever, comparar e distinguir EaD e atividade educacional remota emergencial frente à pandemia da doença COVID-19, os autores concluíram que as atividades educacionais remotas emergenciais não se configuram como $\mathrm{EaD}$, por uma série de fatores que vão desde a legislação, o planejamento e os investimentos em estrutura, até a formação de professores para usos de tecnologias digitais na educação. Ressaltam, ainda, que qualquer implementação de modalidade educativa deve ter como ponto de partida a qualidade da aprendizagem discente (JOYE et al., 2020).

Figura 01: Motivos pelos quais os alunos optaram por participar do PLE.

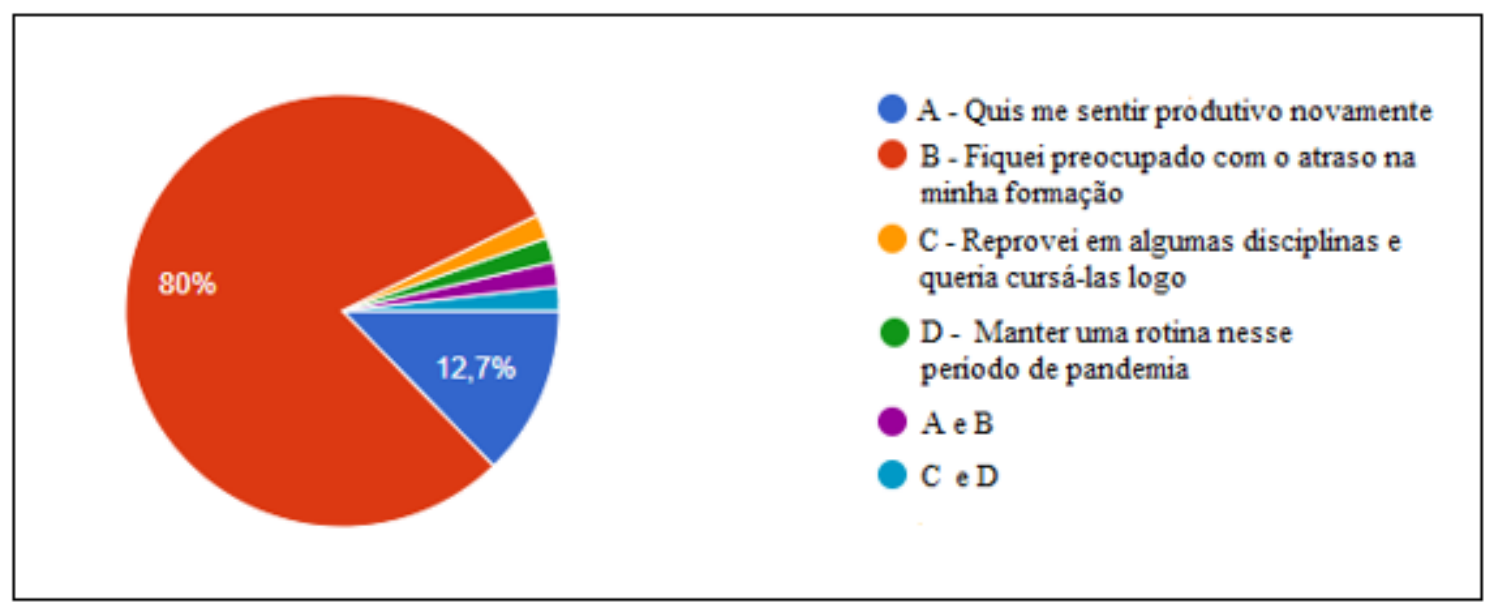

Fonte: Própria (2020).

Na segunda questão, indagou-se aos discentes sobre a saúde mental dos mesmos para a 
realização do PLE (Figura 02). Do total, 30 participantes $(54,5 \%$ ) se sentem bem e não se arrependem de terem cursado a disciplina, 13 participantes $(23,6 \%)$ já não estavam bem e pioraram sua saúde mental ao participar do PLE, 10 participantes $(18,2 \%)$ não estavam bem e sentiram melhora após o início do PLE e 2 (3,6\%) afirmaram estarem emocionalmente aptos ao PLE, mas se arrependeram de fazer a matrícula. Dessa forma, mais de $40 \%$ dos participantes, no momento da pesquisa, se revelaram mentalmente abalados, o que deve exigir da instituição de ensino um maior cuidado com os seus discentes.

Conforme Ribeiro et al. (2020), devido à COVID-19, questões que dizem respeito à saúde mental vêm sendo postas em pauta. O distanciamento e o isolamento social, o excesso de informações disponíveis, situações caóticas e desoladoras decorrentes da perda de parentes e/ou amigos, o próprio enfrentamento da doença ou mesmo o acúmulo de atividades relacionadas ao trabalho e estudo são fatores que podem desencadear como consequência problemas relacionados à saúde psíquica do indivíduo, tais como: estresse, ansiedade, pânico juntamente com sentimentos de solidão, angústia e medo, que podem acarretar em diagnósticos de depressão.

Figura 02: Percepção dos alunos sobre a motivação de participar do PLE e o impacto do PLE na saúde mental dos mesmos.

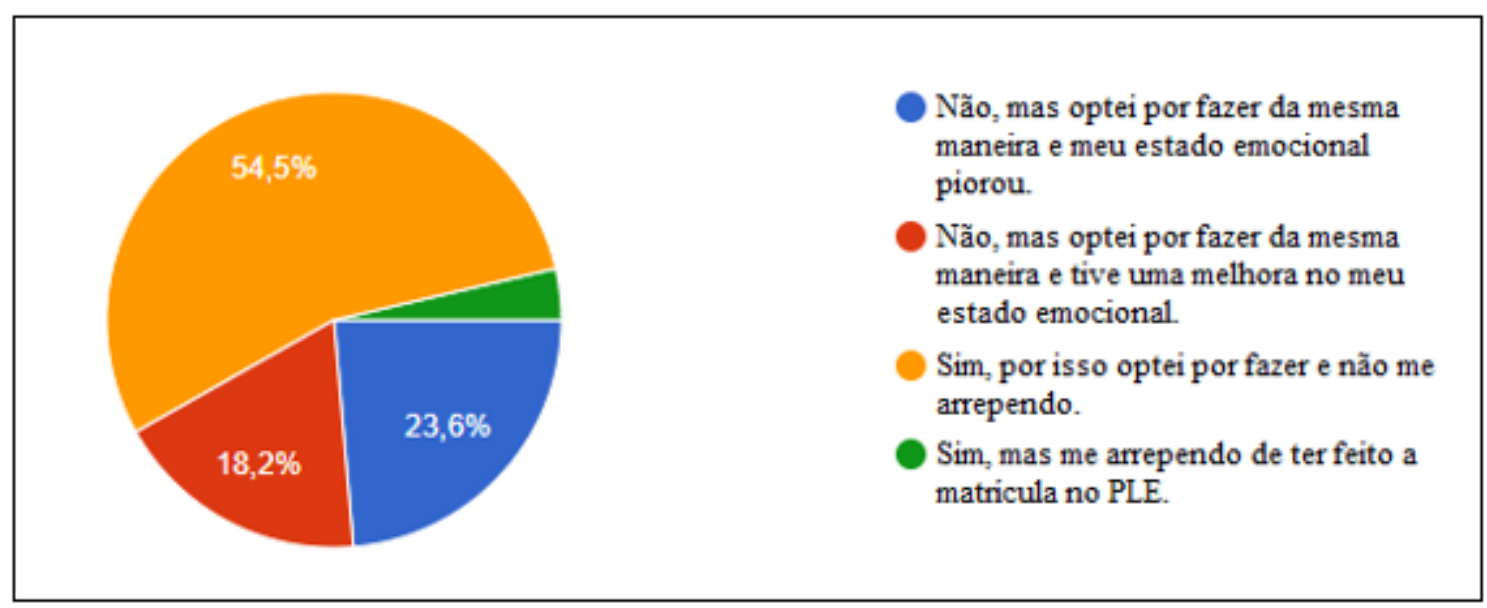

Fonte: Própria (2020).

Na terceira questão, os discentes foram indagados sobre a qualidade de seu acesso à internet durante o PLE. A alternativa que exibia um contexto onde os alunos possuíam conexão ilimitada e que lhes possibilitava um bom acesso aos conteúdos disponibilizados foi marcada por 32 participantes $(58,2 \%)$, porém também foi visto que considerável parte dos alunos (41,8\%) possuíam condições medianas ou ruins de acesso à internet (Figura 03). Diante desse contexto, é necessário que haja uma maior atenção voltada para os alunos que 


\section{PERÍODO LETIVO ESPECIAI: PERSPECTIVAS DE DISCENTES}

não possuem as condições ideais de estudo remoto, a fim de que não ocorram disparidades ao longo do período letivo excepcional.

Conforme dados da pesquisa realizada pelo CETIC (2019), no Brasil 29\% dos domicílios (19,7 milhões de residências) não possuem internet. Destes, 59\% não possuem internet por conta do custo e outros $25 \%$ por conta da dificuldade de acesso à internet nas localidades onde moram. Além disso, $41 \%$ dos entrevistados não possuíam computador para acessar a internet e $49 \%$ não sabiam usá-la. Assim, os estudantes inseridos nos contextos acima citados ficam fora da estratégia do ensino remoto, tendo em vista que geralmente só conseguem o acesso à internet na própria universidade. Tal situação prejudica a formação por conta da diminuição de oportunidades, tais como aproveitar de maneira efetiva as disciplinas ofertadas no PLE.

Em um relato de experiência sobre a educação à distância na crise do Covid-19 em uma instituição de Ensino Superior, $80 \%$ dos alunos indicaram que possuem acesso à internet. No entanto, considera-se também os discentes que reclamaram da falta de acesso à internet, por razões financeiras. Além disso, alguns alunos manifestaram-se junto à Coordenação de Assistência aos Estudantes (CAE) da Instituição em questão, a fim de solicitar apoio em relação a esta problemática (JOYE et al., 2020).

Figura 03: Percepção dos alunos em relação ao acesso à internet durante o PLE.

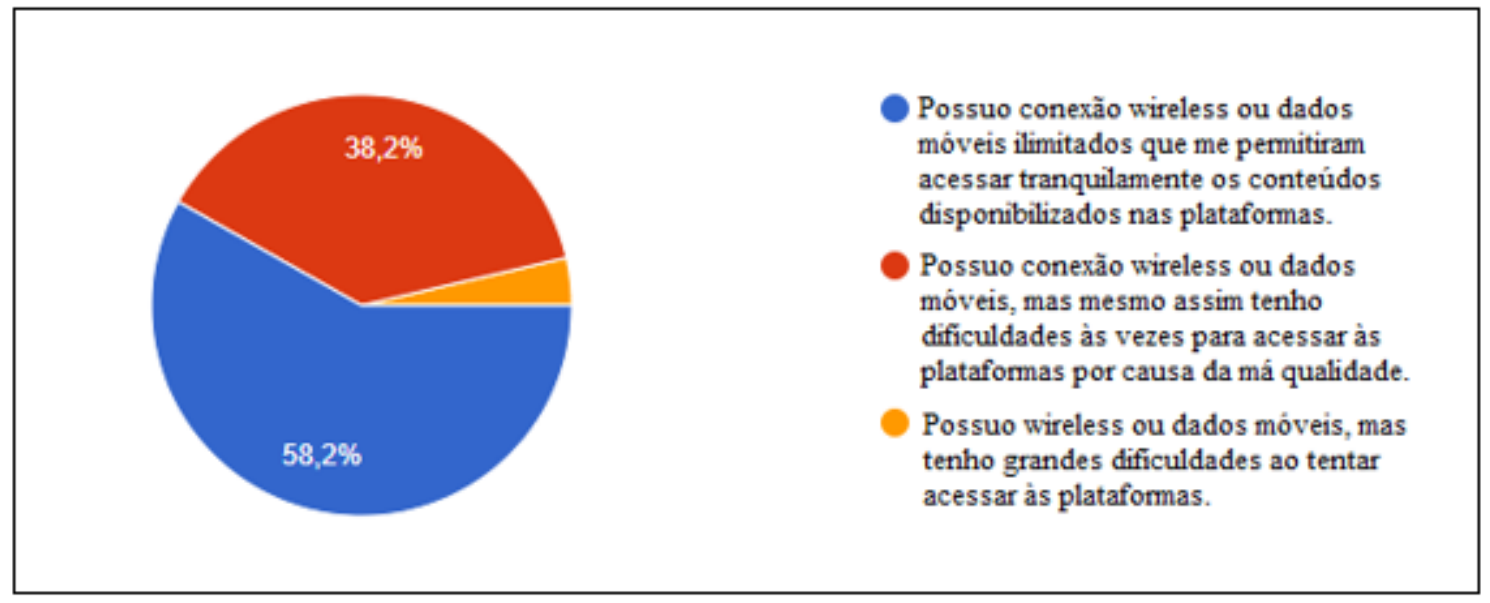

Fonte: Própria (2020).

$\mathrm{Na}$ questão seguinte, os participantes foram questionados sobre suas capacidades de concentração e autodisciplina, pontos ainda mais fundamentais durante o ensino remoto (Figura 04). Observamos que 54,5\% dos participantes afirmaram terem tido dificuldades para se adaptarem a uma nova rotina de estudos, mas que se adequaram com o passar das semanas; 13 participantes $(23,6 \%)$ relataram não terem se adaptado a essa nova rotina. Apenas a 
minoria $(21,8 \%)$ conseguiu se adaptar de imediato e plenamente a essa nova modalidade.

De acordo com Reich et al. (2020) e Hodges et al. (2020), a educação remota em caráter emergencial envolve o uso de soluções de ensino e atividades totalmente remotas, tais como produção de videoaulas através da internet. Essas aulas estão sendo ministradas digitalmente e retornarão ao formato presencial assim que a crise sanitária tiver sido resolvida ou controlada, tendo em vista que são uma mudança temporária para um modo alternativo de ensino. O objetivo principal nessas circunstâncias não é recriar um novo modelo educacional, mas fornecer acesso temporário aos conteúdos e apoios educacionais de uma maneira a minimizar os efeitos do isolamento social nesse processo.

Para Xiao e Li (2020), é sabido que a pandemia da Covid-19 levou a diversas alterações em rotinas e prazos previamente estabelecidos. Alunos enfrentarão atrasos na formação em todos os níveis de ensino e os professores, por sua vez, precisaram se preparar em tempo recorde a esse novo modo de ensino, tendo em vista que não sabemos quando teremos vacinas e/ou quando novas doenças poderão atrapalhar o curso da educação. Os principais desafios encontrados no ensino remoto emergencial são a manutenção do acesso contínuo aos conteúdos e a dificuldade de manter os alunos concentrados e disciplinado; além disso, os docentes precisam trabalhar de forma a deixar o ambiente online interativo e desafiador.

Figura 04: Percepção dos alunos sobre a capacidade de concentração e autodisciplina para estudar durante o PLE.

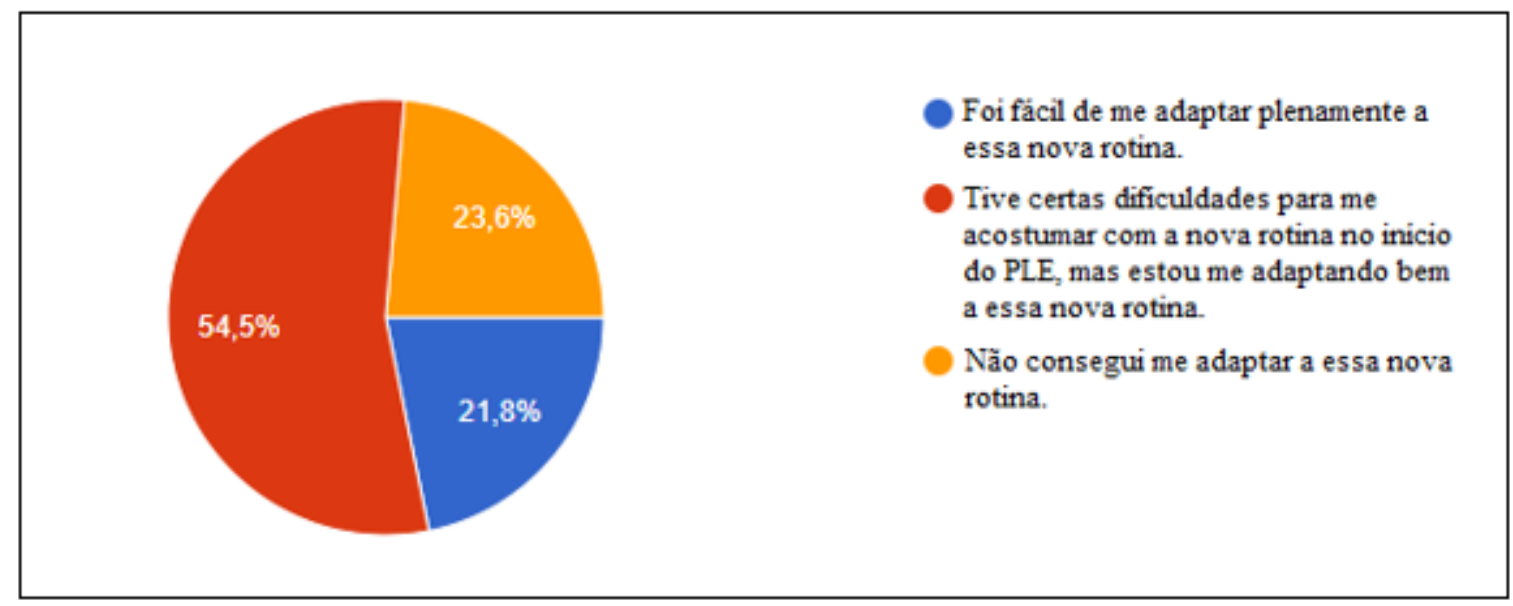

Fonte: Própria (2020).

$\mathrm{Na}$ quinta questão, foi indagado aos alunos se passaram por dificuldades ao tentar se habituarem com as plataformas de ensino online utilizadas nas disciplinas (Figura 05). A alternativa mais frequente (37 discentes - 67,3\%) mostrou que alguns percalços foram 


\section{PERÍODO LETIVO ESPECIAI: PERSPECTIVAS DE DISCENTES}

encontrados ao longo do caminho. Para 12 participantes $(21,8 \%)$ a familiarização foi realizada sem maiores transtornos e, para seis participantes $(10,9 \%)$, houve grandes dificuldades com o manejo dessas plataformas. As dificuldades relatadas pelos alunos podem ser justificadas pela utilização de recursos, que, até então, não eram utilizados com frequência por eles ou que lhes eram totalmente desconhecidos.

WORD BANK (2020) destaca a importância do apoio aos docentes e discentes na transição para o ambiente remoto, tendo em vista que uma transição repentina para o ensino remoto sem considerar a capacidade das universidades em ofertar aulas de qualidade e a dos alunos de ter a estrutura e apoio necessários para passar por tal situação podem elevar ainda mais as desigualdades de aprendizado no Brasil. Os principais fatores envolvidos na queda da aprendizagem nesse processo são a falta de familiaridade com as ferramentas utilizadas no ensino online, a ausência de um ambiente familiar propício ao aprendizado remoto bemsucedido, e a falta de conformidades entre o que era ensino no espaço físico e o que passa a ser ensinado online.

Figura 05: Percepção dos alunos em relação às dificuldades de uso das plataformas online ofertadas no PLE.

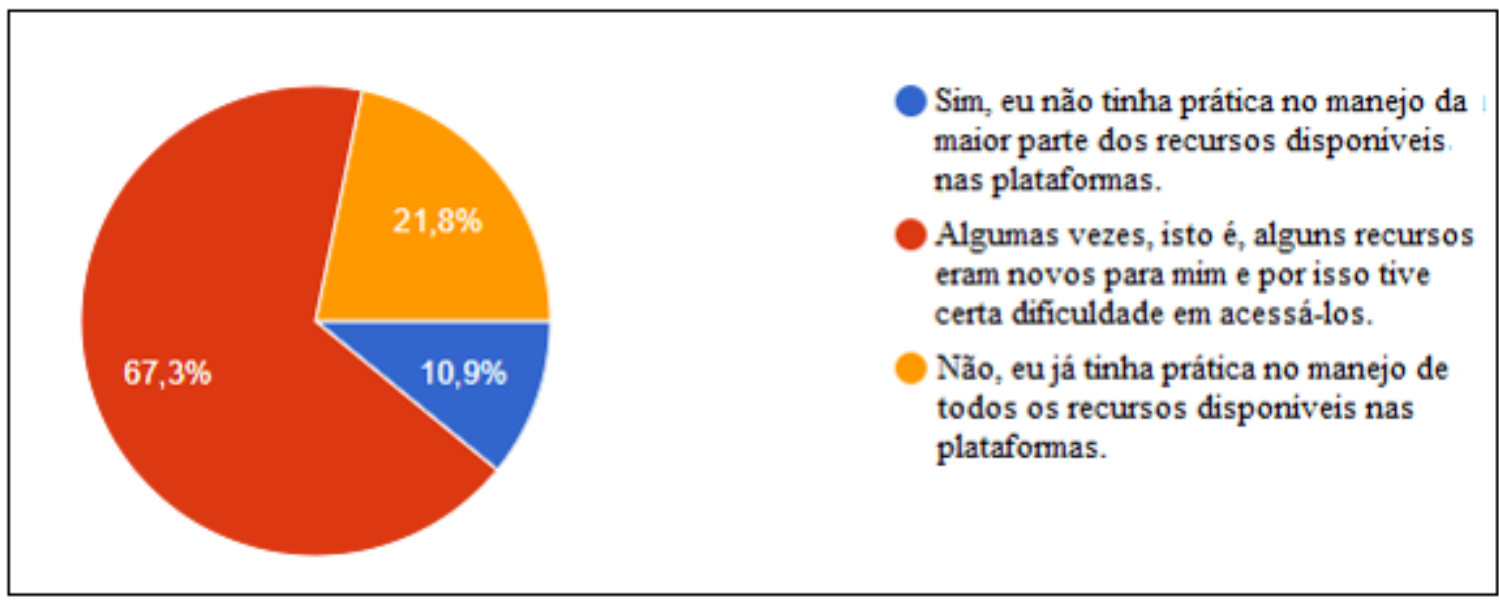

Fonte: Própria (2020).

$\mathrm{Na}$ sexta questão, foi feita uma pergunta discursiva aos alunos, que os questionava sobre sua satisfação com a qualidade das videoaulas e dos conteúdos disponibilizados por seus professores. Dentre as 55 respostas, a maior parte dos estudantes (66\%) declarou que está satisfeita com a qualidade das aulas ministradas e dos conteúdos que estavam sendo passados pelos professores, podendo-se destacar como principais pontos positivos a organização do conteúdo programático e do calendário da disciplina, o perceptível esforço por parte dos docentes para que a disciplina ocorra da melhor forma possível, a correta adequação dos 
professores às recomendações feitas pela universidade e a boa qualidade dos conteúdos propostos. Por outro lado, também foi possível perceber as insatisfações de alguns alunos no que diz respeito a sobrecarga de conteúdo, o curto prazo proposto para a realização das atividades e a dificuldade na comunicação com alguns professores.

Para Cunha e colaboradores (2020), a utilização das tecnologias deve garantir a melhor aprendizagem dos alunos e o acesso ao conhecimento, a fim de possibilitar a aprendizagem. Entretanto, tal possibilidade engloba diversos sentidos, e a aprendizagem pode estar prejudicada em modelos EaD e, mais ainda, em um ensino remoto que surge, apressadamente, nas tensões da pandemia. Tal situação nos leva a pensar em um modelo de sociedade mais igualitário, com melhoria à formação docente, principalmente no que diz respeito às TICs, além de projetos que garantam o direito à educação e igualdade de condições de acesso.

$\mathrm{Na}$ sétima questão, os discentes foram indagados a respeito de quais alinhamentos regiam os métodos avaliativos utilizados nas disciplinas no PLE (Figura 06). Majoritariamente (46 discentes - 83,6\%) a alternativa mais selecionada pelos participantes foi a que evidenciava um contexto no qual professores faziam o uso de avaliações tradicionalistas associadas a metodologias mais modernas, isto é, uma avaliação mista. Apenas uma reduzida parcela dos alunos marcou as alternativas que falavam sobre uma avaliação somente tradicionalista $(10,9 \%)$ ou somente baseada na subjetividade $(5,5 \%)$. Tais resultados demonstram que os professores se esforçaram para permitir ao aluno uma maior quantidade de metodologias de avaliação, a fim de estimulá-los de acordo com o que possuem mais afinidade.

Em se tratando de ensino, é evidente que o docente possui um papel a cumprir, mas ele não pode ser entendido como agente exclusivo da produção do conhecimento; entre outros fatores, o estudante deve ser compreendido e estimulado a ser também responsável por sua formação intelectual. Há docentes reconhecendo o excesso de atividades e que esse fato desestimula os processos de ensino e aprendizagem; dessa forma, alguns estão priorizando temas geradores, de parceria inter e transdisciplinar, favorecendo a ligação dos saberes e potencialização dos mesmos em relação à vida dos estudantes, fazendo com que o processo de ensino-aprendizagem seja gerador de sentido entre conteúdos teóricos e práticos (JOYE et al., 2020).

Figura 06: Percepção dos alunos em relação aos métodos avaliativos dos professores no PLE. 


\section{PERÍODO LETIVO ESPECIAI: PERSPECTIVAS DE DISCENTES}

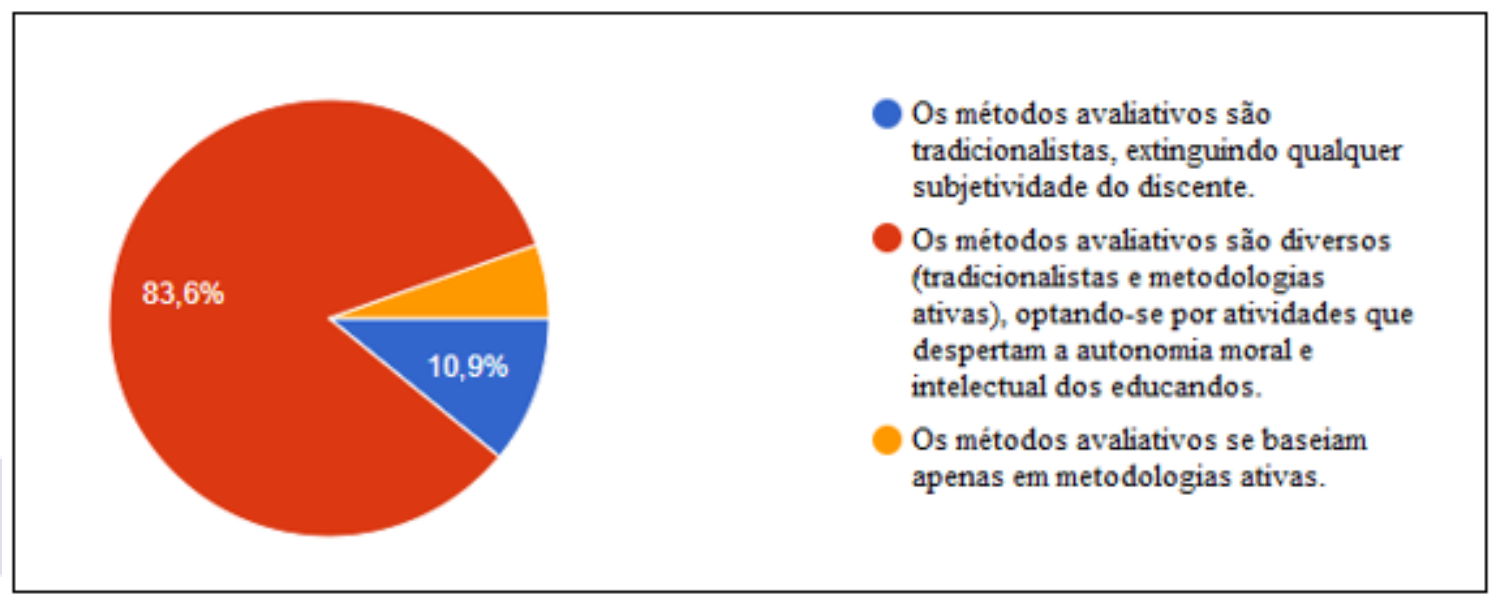

Fonte: Própria (2020).

$\mathrm{Na}$ oitava questão, os discentes foram indagados acerca de suas percepções no que diz respeito à construção do conhecimento durante o PLE (Figura 07). Do total, 36 participantes $(65,5 \%)$ afirmaram que seu desempenho e aproveitamento, quando comparado aos períodos presenciais, se mantiveram; também foi visto que 12 participantes $(21,8 \%)$ afirmaram terem tido uma piora no seu desempenho e apenas sete declararam um apresentar uma considerável melhora durante o PLE.

Figura 07: Percepção dos alunos em relação ao seu desempenho e construção do conhecimento no PLE.

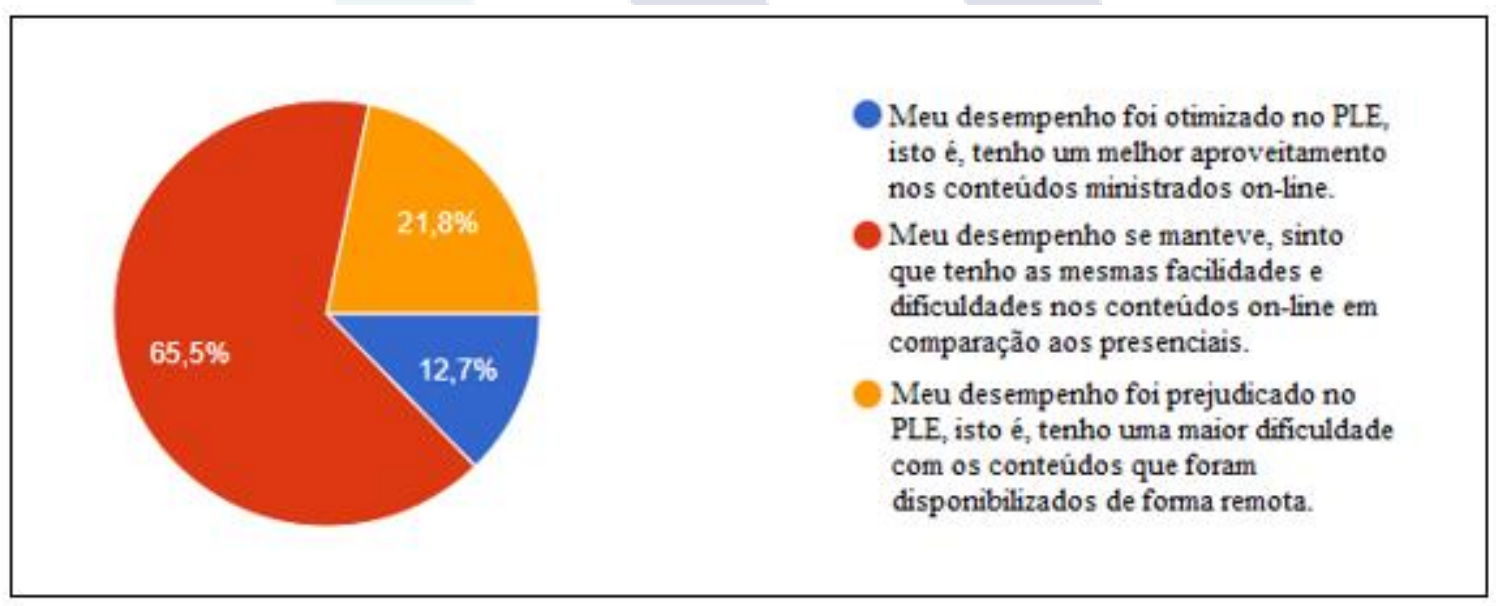

Fonte: Própria (2020).

$\mathrm{Na}$ nona questão, foi perguntado aos participantes se, com base em suas experiências, eles recomendariam a continuação dessa forma de ensino em algumas disciplinas mesmo após o retorno das aulas presenciais (Figura 08). Foi observado que 54,5\% dos entrevistados deram uma resposta negativa quanto à associação do ensino remoto com o ensino presencial, sendo a minoria $(27,3 \%)$ os alunos que apresentaram resposta positiva para essa possibilidade. Tal 
resultado era esperado, tendo em vista que são alunos oriundos do período presencial, que jamais imaginaram que, de uma hora pra outra, se veriam assistindo aula através do ensino remoto.

Apesar de os estudantes não estarem acostumados com uma forma de educação semelhante ao $\mathrm{EaD}$, a educação remota é um princípio importante para manter o vínculo entre estudantes, professores e demais profissionais da Educação. A resposta em contrário pode representar o afastamento por muitos meses de estudantes dos espaços escolares (físicos e virtuais), o que pode comprometer a qualidade da educação, possivelmente mais do que a implementação de iniciativas que mantenham tais vínculos, apesar das limitações que venham a conferir (ARRUDA, 2020).

Figura 08: Possível recomendação do ensino remoto pelos discentes após a retomada do ensino presencial pela Universidade.

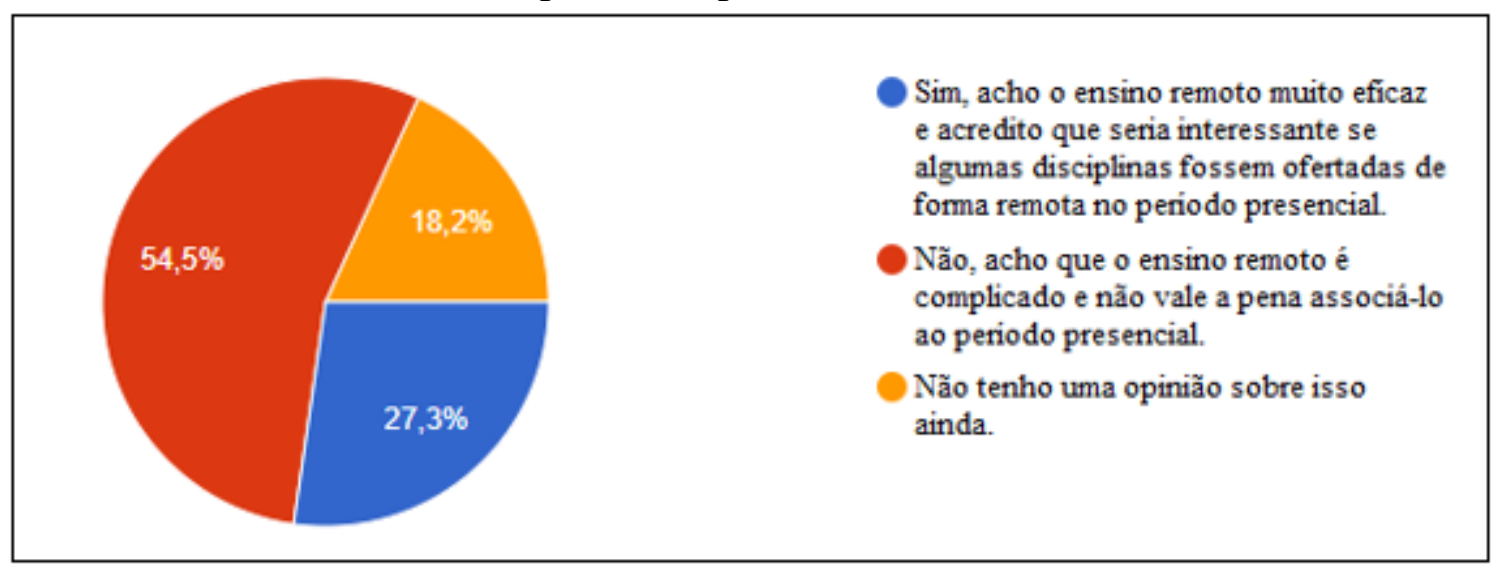

Fonte: Própria (2020).

$\mathrm{Na} 10^{\circ}$ questão, foi perguntado aos discentes as principais dificuldades que tiveram durante o PLE. Os principais percalços relatados podem ser divididos em questões relacionadas à infraestrutura, de âmbito pessoal e questões relacionadas exclusivamente às disciplinas cursadas. Problemas relacionados à internet e mau funcionamento de computador/ notebook e celular foram relatados dez vezes.

Problemas com a organização dos horários, questões psicológicas e familiares e dificuldades em manter uma autodisciplina foram desafios relatados 20 vezes. A alta carga de conteúdos disponibilizados, prazos, dificuldades na comunicação professor-aluno, preocupações a respeito da relação entre os conteúdos a serem abordados e o tempo limite do PLE foram relatados mais de dez vezes dentre os participantes. Além disso, também foram vistas questões a respeito da pouca quantidade de disciplinas ofertadas para o período. 


\section{PERÍODO LETIVO ESPECIAI: PERSPECTIVAS DE DISCENTES}

Por fim, na última pergunta, foi pedido aos alunos que sugerissem melhorias a serem feitas para potencializar o funcionamento do PLE. Seguindo o padrão da questão anterior, sugestões de reavaliação na quantidade de conteúdos disponibilizados se repetiram e fizeram parte do depoimento de 9 participantes. Um dos discentes escreveu que "é preciso analisar novamente a quantidade de horas que os alunos e professores precisarão se dedicar, porque, dependendo da semana ou das atividades, se torna algo muito cansativo". Outra ideia levantada por 9 estudantes foi a necessidade de atividades mais interativas e menos tradicionalistas, como por exemplo: "utilizaria metodologias ativas com mais frequência (ex. aprendizagem baseada em problemas e projetos), diminuiria atividades passivas de leitura de textos e aplicação de questionários e tentaria explorar mais ferramentas digitais, além do $A V A "$.

A requisição de mais aulas síncronas esteve presente na sugestão de 8 alunos, tornando notável o carecimento pelo espaço da sala de aula. Entretanto, isso não representa a totalidade dos discentes, pois houve sugestões contrárias ao aumento de momentos síncronos, que se justificavam pela indisponibilidade provocada pela alteração na rotina. Além desses levantamentos, 3 alunos citaram que seria uma boa ideia a instituição disponibilizar aos professores meios para a capacitação mais adequada às condições de ensino remoto.

\section{CONCLUSÕES}

Diante dos impactos causados ao sistema educacional brasileiro oriundos da pandemia gerada pela COVID-19, é incontestável dizer que o Período Excepcional Letivo e o ensino remoto se demonstraram essenciais para que os processos de ensino-aprendizagem nas instituições de ensino superior tivessem continuidade. Entretanto, em virtude do que foi relatado pelos participantes e analisado posteriormente nesta presente pesquisa, se torna possível afirmar com clareza que detalhes cruciais devem ser revistos pela comunidade educacional, a fim de aperfeiçoar tanto o ensino remoto, quanto sua vertente em contexto emergencial.

Ao longo da construção deste artigo, observou-se que o ensino remoto requer uma infraestrutura e pilares específicos para que decorra seu bom funcionamento. Destarte, é imprescindível ressaltar aqui que as instituições de ensino que adotaram tal modalidade devem se ater às particularidades de seus discentes.

O acesso aos conteúdos disponibilizados de forma remota já é uma questão que tem presença caracterizada por inconformidades mesmo sob um contexto dito como normal, e que, de acordo com o que foi relatado, não se abrandou quando o cenário pandêmico foi 
instalado. Por outro lado, foi possível notar a presença de dois outros fatores que se consistiam em grandes adversidades para o bom desempenho dos participantes em suas disciplinas: a instabilidade na saúde mental, gerada pelo conjuntura pandêmica, e a sobrecarga de afazeres. Observou-se que esses três fatores estabelecem uma relação entre si, engendrando um esquema que acaba por reforçar cada vez mais uns aos outros, visto que a dificuldade no acesso aos conteúdos acarreta no acúmulo de atividades e possivelmente numa piora no estado emocional por não conseguir realizar o que precisa; da mesma forma que um indivíduo com saúde mental já abalada pode por si só se sentir incapaz de realizar seus compromissos em tempo hábil. Portanto, esses três obstáculos formam a principal frente contra o atual processo de ensino-aprendizagem, impedindo que esse se concretize de maneira eficaz.

Nessa perspectiva, constata-se um contexto amplo e bastante complexo, mas que da mesma maneira pode se tornar um terreno propício para repensar as diretrizes da educação brasileira, afinal, a pandemia gerada pelo COVID-19 expôs de maneira axiomática os problemas e desafios a serem enfrentados pelo sistema educacional brasileiro. Conclui-se, então, que é um momento de reconhecimento de fragilidades e potencialidades da modalidade remota e da comunidade educacional como um todo - incluindo aqui tanto infraestrutura quanto os docentes, estudantes e gestores - , para que a reorganização dos ambientes de ensino no pós-pandemia seja feita da melhor forma possível, visando o aspecto qualitativo do processo educativo. É necessário ainda levar em considareção que o processo de retorno à sala de aula acontecerá de uma maneira totalmente distinta e que o processo de ensino e aprendizagem não será retomado do ponto em que fora deixado quando houve a suspensão das atividades presenciais.

\section{REFERÊNCIAS}

ARRUDA, E. C. Educação remota emergencial: elementos para políticas públicas na educação brasileira em tempos de Covid-19. EmRede - Revista de Educação a Distância, [S.I], v. 7, n. 1, p. 257-275, maio 2020

BARRETO, A. C. F.; ROCHA, D. S. COVID 19 e educação: resistências, desafios e (im)possibilidades. Encantar - Educação, Cultura e Sociedade, Bom Jesus da Lapa, vol. 2, p. 01-11, jan./dez. 2020.

BRASIL ${ }^{\text {a }}$ Portaria $\mathbf{n}^{\mathbf{0}}$ 343, de 17 de março de 2020. Dispõe da substituição das aulas presenciais por aulas em meios digitais enquanto durar a situação de pandemia do novo coronavírus - COVID-19. Brasília. DOU - Diário Oficial da União. Publicado em 17 de março de 2020.

BRASIL ${ }^{\mathrm{b}}$. Portaria $\mathbf{n}^{0}$ 544, de 16 de junho de 2020. Dispõe da substituição das aulas 


\section{PERÍODO LETIVO ESPECIAI: PERSPECTIVAS DE DISCENTES}

presenciais por aulas em meios digitais enquanto durar a situação de pandemia do novo coronavírus - COVID-19. Brasília. DOU - Diário Oficial da União. Publicado em 16 de junho de 2020.

CASTAMAN, A. S.; RODRIGUES, A. R. Educação a Distância na crise COVID - 19: um relato de experiência. Research, Society and Development, v. 9, n. 6, e180963699, abr. 2020.

CETIC. Pesquisa sobre o Uso das Tecnologias de Informação e Comunicação nos domicílios brasileiros - TIC Domicílios. NIC. São Paulo, 2019. Disponível em: $<$ http://data.cetic.br/cetic/explore> Acesso em: 20 out. 2020.

CUNHA, L. F. F.; SILVA, A. S.; SILVA, A. P. O ensino remoto no Brasil em tempos de pandemia: diálogos acerca da qualidade e do direito e acesso à educação. Revista Com Censo, Brasília, vol. 7, n. 3, p. 27-37, ago. 2020.

HODGES, C. et al. The difference between emergency remote teaching and online learning. Educause Rev. 27 mar. 2020. Disponível em <https://er.educause.edu/articles/2020/3/thedifference-between-emergency-remote-teachingand-online-learning $>$ Acesso em: 12 de out. 2020.

JOYE, C. R.; MOREIRA, M. M.; ROCHA, S. S. D. Educação a Distância ou Atividade Educacional Remota Emergencial: em busca do elo perdido da educação escolar em tempos de COVID-19. Research, Society and Development, v. 9, n. 7, e521974299, maio 2020.

LANA, R. M. et al. Emergência do novo coronavírus (SARS-CoV-2) e o papel de uma vigilância nacional em saúde oportuna e efetiva. Cadernos de Saúde Pública, [S.I] vol. 36, n. 3, mar. 2020.

PASINI, C. G. D.; CARVALHO. E.; ALMEIDA, L. H. C. A educação híbrida em tempos de pandemia: algumas considerações. OSE - Observatório Socioeconômico da COVID-19, Rio Grande do Sul, jun. 2020.

REICH, J. et al. Remote Learning Guidance From State Education Agencies During the COVID-19 Pandemic: A First Look. EdArXiv, 2 apr. 2020. Disponível em: <https://doi.org/10.35542/osf.io/437e2> Acesso em: 15 de out. 2020.

RIBEIRO, E. G. et al. Saúde mental na perspectiva do enfrentamento à COVID-19: Manejo das consequências relacionadas ao isolamento social. Revista Enfermagem e Saúde Coletiva, São Paulo, vol. 5, nº 1, p. 47- 56, jul. 2020.

SENHORAS, E. M. Coronavírus e educação: análise dos impactos assimétricos. BOCA, Boa Vista, vol. 2, n. 5, p. 128-136, maio 2020.

SILVA, E. H. B.; NETO, J. G. S.; SANTOS, M. C. Pedagogia da pandemia. Revista LatinoAmericana de Estudos Científicos, vol. 1, n 4, p. 29-44, jul. 2020.

TODOS PELA EDUCAÇÃO. Nota Técnica: Ensino a Distância na educação básica frente à pandemia da COVID-19. Abr, 2020. 
WBG - WORLD BANK GROUP EDUCATION. Políticas educacionais na pandemia da COVID-19: o que o Brasil pode aprender com o resto do mundo?. World Bank Group Education, abr. 2020. Disponível em: $<$ https://americanethnologist.org/features/collections/covid-19-and-student-focused-concernsthreats-and-possibilities/analysis-on-the-influence-of-epidemic-on-education-in-china> Acesso em: 4 de set. 2020.

XIAO, C.; LI, Y. Analysis on the Influence of Epidemic on Education in China. American Ethnological Society. 1 may, 2020. Disponível em: $<$ https://americanethnologist.org/features/collections/covid-19-and-student-focused-concernsthreats-and-possibilities/analysis-on-the-influence-of-epidemic-on-education-in-china> . Acesso em: 1 de set. 2020. 